\title{
Allergic inflammatory responses induced by traffic- related PM2.5 in BALB/c mice
}

Hai Ying Wei ( $\nabla$ weihaiying@sxu.edu.cn )

Shanxi University

Huan Yu

College of Environmental and Resources Science Sciences Chinese Academy of Sciences

Lifeng Zhang

Coal Geological Geophysical Exploration Surveying \& Mapping Institure of Shanxi Province

Zhenyu Dong

Shandong Institute of Scientific and Technical Information

\section{Research Article}

Keywords: Traffic-related PM2.5, IL-4, IL-17A, IL-10, Histopathology, Allergic inflammation

Posted Date: October 20th, 2021

DOI: https://doi.org/10.21203/rs.3.rs-926545/v1

License: (c) (1) This work is licensed under a Creative Commons Attribution 4.0 International License. Read Full License 


\section{Abstract}

Previous studies have shown that $\mathrm{PM}_{2.5}$ is associated with airway inflammation and lung injury. However, the association between traffic-related $\mathrm{PM}_{2.5}$ (TR-PM) exposure and OVA-induced allergic inflammation is not fully elucidated. In this study, we assessed allergic inflammatory responses of mice induced by TRPM. $\mathrm{PM}_{2.5}$ was collected from a roadside with heavy traffic, and its soluble extract was prepared. Mice were treated with OVA, TR-PM alone, and OVA + TR-PM. The inflammatory cells were counted, and inflammation-related cytokines IL-4, IL-17A, and IL-10 in bronchoalveolar lavage fluid (BALF) were determined by the radioimmunity assay. Allergy-induced inflammation and lung injury were investigated by histopathological analyses. The expression of IL-4, IL-17A, and IL-10 mRNA was analyzed by RT-PCR. Our results revealed that TR-PM exposure, combined with OVA allergen sensitization, increased the inflammatory cells in BALF as well as levels of IgE in lung tissue; increased the IL-4 and IL-17A levels in BALF significantly, but decreased IL-10 level. The histopathologic results demonstrated that TR-PM markedly exacerbated the OVA-induced neutrophilic granulocyte, lymphocyte, and macrophage infiltration. Furthermore, the expression of IL-4, IL-17A and IL-10 mRNA was well in agreement with the results of the inflammatory cytokines. In conclusion, during the sensitization to allergic antigens, TR-PM exposure triggers severe allergic inflammation and lung injury. These findings suggest that commuters should use public transportation instead of riding motorcycles or walking during rush hours.

\section{Introduction}

According to the World Health Organization (WHO), air pollution in cities and rural areas caused an estimated 4.2 million premature deaths worldwide in 2016, and ambient particulate matter $\left(\mathrm{PM}_{2.5}\right)$ has been identified as a potential risk factor (Pinkerton et al., 2019). $\mathrm{PM}_{2.5}$ can penetrate deep into the lungs, deposit in the airways and alveoli, and pass into circulation. These effects elicit responses in pulmonary and extrapulmonary tissues (Yuan et al., 2020) that trigger asthma and increases the risk of respiratory allergic disorders (He et al., 2016; Gorail et al., 2016; Kirrane et al., 2019; Li et al., 2019). Epidemiological evidences suggest that $\mathrm{PM}_{2.5}$ contributes to increased hospitalization and emergency visits of asthma (Gehring et al., 2015; Loftus et al., 2015).

As most major pollutants, $\mathrm{PM}_{2.5}$ originate from construction sites, power plants, coal combustion, oil combustion, biomass aerosol and vegetative detritus (Mimura et al., 2014; Edginton et al., 2021). In-vitro experiments have shown that different compositions of $\mathrm{PM}_{2.5}$ have different effects inducing proinflammatory response, oxidative stress, and DNA damage in cells (Gutierrez-Castillo et al., 2006; Yang et al., 2016; Gehring et al., 2015; Krall et al., 2013, 2017). Traffic emissions are a major source of aerosol particles in the urban environment (Rönkkö et al., 2017), which account for about $40 \%$ of the PM mass in the atmosphere (Dai et al., 2015; Wu et al., 2021). Diesel and gasoline include high levels of elemental carbon (EC) and organic carbon (OC), which are associated with the most increased risks of emergency hospitalization among the major constituents of ambient $\mathrm{PM}_{2.5}$ (Peng et al., 2009). PAHs have been 
frequently identified as a dominant pollutant from vehicle exhaust $\mathrm{PM}_{2.5}$, greatly impacting human health (Abdel-Shafy and Mansour, 2016).

People in large cities are close to traffic emissions and exposed to high-level traffic-related air pollution, especially during rush hours, which may significantly impact their health (Kaur et al., 2007). In recent years, the rapidly increasing number of vehicles in large cities leads to classical modern traffic air pollution in China. It has been reported that traffic-related pollutants, including $\mathrm{NO}_{2}$, elemental carbon, and particulate matter, have a significant impact on the cognition and developmental nervous systems and respiratory system of students (An et al., 2021). The prevalence of asthma among urban children has increased dramatically from 1.5-6.8\% over the past decades (Zhang et al., 2013). Therefore, exposure to traffic-related air pollution remains a major public health issue in urban areas with heavy traffic worldwide.

Although many studies have been conducted on $\mathrm{PM}_{2.5}$ and human health, few studies have focused on the effect of traffic related $\mathrm{PM}_{2.5}$, This study aimed to identify the allergic inflammatory response of mice to traffic $\mathrm{PM}_{2.5}$. We collected $\mathrm{PM}_{2.5}$ from a roadside with heavy traffic, and then administered into the airways of mice. The purpose was to investigate whether the traffic-related $\mathrm{PM}_{2.5}$ (TR-PM) induces allergic airway inflammation. The investigation included examining cytological alteration in BALF, changes in inflammatory cytokines and ovalbumin (OVA) specific IgE antibodies in serum. Pathologic change and mRNA expression of inflammatory factors in the lung tissue were also investigated during the phase of allergic sensitivity in the mice models.

\section{Methods And Materials}

\subsection{Sample collections of TR-PM}

The TR-PM samples were collected from a traffic-dominated site (Xuefu street) in Taiyuan $\left(37^{\circ} 49^{\prime} \mathrm{N}\right.$, $\left.112^{\circ} 34^{\prime} \mathrm{E}\right)$, China, from 1 st to 31 st July 2019 . The sampling site represents a traffic-dominated site located at the center of the city, which is the most crowded street, Xuefu Street. Samples were collected on $3 \mu \mathrm{m}$ pore size quartz microfiber filters (Whatman) using a high-volume particle collector with a flux of $1.13 \mathrm{~m}^{3} / \mathrm{min}$ (Thermo Anderson, USA). The collection duration of each sample was $24 \mathrm{~h}$ with filters being exchanged at 7 am every day. The quartz filters were preheated at $450^{\circ} \mathrm{C}$ for $6 \mathrm{~h}$ before sampling.

\subsection{Analysis of components in the TR-PM}

Polycyclic aromatic hydrocarbons (PAHs) were analyzed according to previously reported methods (Wei et al., 2019). Briefly, quartz filter membranes containing $\mathrm{PM}_{2.5}$ samples were cut into pieces, put into 10 $\mathrm{mL}$ centrifuge tubes, and extracted with dichloromethane (DCM) by ultrasonic cleaning three times for 15 $\min$. The extracts were concentrated to about $1 \mathrm{~mL}$ on a rotary evaporator, purified on a silica gel packed column, and then concentrated to $0.5 \mathrm{~mL}$ under a gentle nitrogen stream in a $60^{\circ} \mathrm{C}$ water bath. The PAH analysis was conducted by GC-MS (Agilent 6890 GC coupled with 5975 MSD) in selected ion monitoring 
(SIM) mode similar to previous studies (Li et al., 2014). All samples were analyzed more than twice to reduce measurement errors. The PAHs analysis included naphthalene (NAP), acenaphthylene (ANY), acenaphthene (ANA), fluorene (FLU), phenanthrene (PHE), anthracene (ANT), fluoranthene (FLT), pyrene (PYR), ben-zo[a]anthracene $(\mathrm{BaA})$, chrysene $(\mathrm{CHR})$, benzo[b]fluoranthene $(\mathrm{BbF})$, benzo[k] fluoranthene (BkF), benzo[a]pyrene (BaP), indeno[1,2,3-cd]pyrene (IcdY), dibenzo[a,h]anthracene (DahA), and benzo[g,h,i]perylene (BghiP) obtained from Chem Service Inc. (West Chester, PA, USA).

The contents of organic carbon (OC) and element carbon (EC) in TR-PM were determined by thermo optic carbon analyzer (DRI model 2001a) according to the advanced analysis protocol (TOR METHOD) (Chow et al.,2007). The accuracy and detection limits of the instrument were calibrated by using the blank filter membrane before sample measurement. The quartz filter membrane containing $\mathrm{PM}_{2.5}$ sample was heated to $140{ }^{\circ} \mathrm{C}, 280^{\circ} \mathrm{C}, 480{ }^{\circ} \mathrm{C}$ and $580^{\circ} \mathrm{C}$ in pure helium without oxygen. The $\mathrm{OC}_{1}, \mathrm{OC}_{2}, \mathrm{OC}_{3}$ and $\mathrm{OC}_{4}$ in organic carbon were detected, respectively. The carrier gas was then converted to $98 \%$ helium/ $2 \% \mathrm{O}_{2}$, and the membrane was heated to $580{ }^{\circ} \mathrm{C}, 740{ }^{\circ} \mathrm{C}$ and $840{ }^{\circ} \mathrm{C}$ to detect $\mathrm{EC}_{1}, \mathrm{EC}_{2}$ and $\mathrm{EC}_{3}$, respectively. Part of the organic carbon was converted into pyrolytic carbon (OPC) under no oxygen heating. The sample was irradiated by a $633 \mathrm{~nm}$ laser and the pyrolytic organic carbon was detected. The contents of $\mathrm{OC}, \mathrm{EC}$ and $\mathrm{TC}$ were calculated according to the following eight components: $\mathrm{OC}=\mathrm{OC}_{1}+\mathrm{OC}_{2}+\mathrm{OC}_{3}+\mathrm{OC}_{4}$ $+\mathrm{OPC} ; \mathrm{EC}=\mathrm{EC}_{1}+\mathrm{EC}_{2}+\mathrm{EC}_{3}-\mathrm{OPC} ; \mathrm{TC}=\mathrm{OC}+\mathrm{EC}$.

\subsection{TR-PM extraction}

TR-PM samples were extracted from sampled filter strips according to Bein and Wexler method (Bein and Wexler, 2015). The sample filters were weighed to calculate the PM concentration, placed in Milli-water and sonicated for 1 hour. The extract was filtered using a $0.2 \mu \mathrm{m}$ pore size syringe filter. The collected solution was lyophilized and then resuspended in Milli-Q water to a $1 \mathrm{mg} / \mathrm{mL}$ final PM concentration. It should be noted that possible side effects of the PM size and composition from the procedure could not be entirely avoided.

\subsection{Animals}

BALB/c mice (7-weeks old) were purchased from the Beijing Vital River Laboratory Animal Technology Co., Ltd. (Beijing, China). All animal procedures were approved by the Shanxi University's Institutional Animal Care and Use Committee and handled according to the National Institute of Health guidelines. Animals were housed in an air-conditioned room with temperatures $22-25^{\circ} \mathrm{C}, 40 \% \pm 55 \%$ humidity, and a 12-h light/dark cycle. They were fed with restricted ovalbumin (OVA) free food and water for one week before the beginning of the experiment.

\subsection{Study protocol}

A total of 40 male BALB/c mice were randomly divided into 4 exposure groups (each group $n=10$ ) that were sensitized/challenged with one of the following: 1) Vehicle control (phosphate-buffered saline, PBS)/PBS, 2) OVA/OVA 3) TR-PM/PBS, 4) OVA + TR-PM/OVA. The detailed exposure protocol is depicted in Fig. 1. On days 1, 3, and 5, mice were exposed to PBS, OVA, TR-PM and OVA + TR-PM. Mice then had a 
1-week recovery period from dosing. Mice were subsequently challenged on day $12 \sim 14$ to either PBS (control and TR-PM groups) or OVA (OVA and OVA + TR-PM groups). PBS, OVA, TR-PM, and OVA + TR-PM were delivered to the lungs of mice via oropharyngeal aspiration after mice were anesthetized via inhalation of isoflurane and oxygen ( $2 \%$ isoflurane, $1 \mathrm{~L} / \mathrm{min}$ oxygen) (Carosino et al., 2015). OVA was administered at a dose of $10 \mu \mathrm{g} / \mathrm{d} /$ mouse, and TR-PM was administered at $33.3 \mu \mathrm{g} / \mathrm{d} / \mathrm{mouse}$ (the total dose for the 3 days was $100 \mu \mathrm{g}$ ). In the OVA + TR-PM group, OVA and TR-PM were exposed separately, approximately $15 \mathrm{~min}$ apart, to avoid particle-protein interactions. For each exposure group, six animals were used to collect BALF, while four animals were used for histological assessment only.

One day after the last challenge, mice from all groups were anesthetized by intraperitoneal injections of pentobarbital $(45 \mathrm{mg} / \mathrm{ml})$ and euthanized by exsanguination.

\subsection{Bronchoalveolar Lavage Fluid (BALF) and cellular Analysis}

A subset of six mice per exposure group was used to examine the contents of the free cells from BALF. The lungs were lavages with two volumes of $0.7 \mathrm{ml}$ of sterile PBS by a syringe. The collected lavage fluid was centrifuged at $4^{\circ} \mathrm{C}$ at $2000 \times \mathrm{g}$ for $15 \mathrm{~min}$ to pellet the cells, and the supernatants were stored at $-80^{\circ} \mathrm{C}$ until analyzed for cytokines. The cells were resuspended in $30 \mu \mathrm{l}$ cold PBS, and the total cell count of a fresh fluid specimen was determined using a hemocytometer. Differential cell counts were assessed on cytologic preparations (Sun et al., 2017).

\subsection{Quantitation of Cytokines in BALF}

The cytokine protein levels in the BALF were measured using an enzyme-linked immunosorbent assay (ELISA). Interleukin (IL)-4, IL-17A, and IL-10 were measured by ELISA kits (Westang Biotechnology Co., Shanghai, China) according to the manufacturer's protocol.

\subsection{Plasma collection and Antigen-specific IgE antibodies analysis}

Blood was collected immediately following euthanasia via cardiac puncture in EDTA-coated cryotubes (Taizhou Taianyi Medical Devices C., Ltd, Taizhou, China) and centrifuged at $1000 \times \mathrm{g}$ for $15 \mathrm{~min}$ at $4^{\circ} \mathrm{C}$ to collect plasma. Plasma was collected and stored at $-80^{\circ} \mathrm{C}$ until analyzed for OVA-specific lgE (OVA-lgE) .

OVA-IgE antibodies were measured by a Mouse OVA-IgE ELISA kit (Westang Biotechnology Co., Shanghai, China) according to the manufacturer's protocol. The absorption at $450 \mathrm{~nm}$ (sub-wavelength $620 \mathrm{~nm}$ ) for OVA-IgE was measured using a microplate reader (Bio-rad 550, USA).

\subsection{Histological analysis}

Four of 10 mice from each group were used for histological examination. Lungs were collected and fixed in $4 \%$ paraformaldehyde (Sigma, USA). Then the tissues were dehydrated with graded alcohol, embedded in paraffin, and cut into 5- $\mu \mathrm{m}$ sections. The sections were stained with hematoxylin and eosin stain (H \& 
E, Harris Hematoxylin, and Eosin Y Stain: American MasterTech). Finally, Lung tissue sections were examined for inflammation, cellular infiltrates and blood vessels, airways. Ten random fields per section were observed by light microscopy (Olympus, Japan) at 100X magnification.

\subsection{RT-PCR analysis}

Total RNA was isolated from lung tissues using TRIzol reagent (Transgen, Beijing, China) according to the manufacturer's instructions. Total RNA was reverse transcribed to cDNA using Reverse Transcription Reagents (Thermo Fisher, USA). The expression of IL-4, IL-17A, and IL-10 was measured by quantitative real-time PCR using Biorad IQ5 (USA). All protocols were performed according to the manufacturer's instructions. The experiments were repeated at least three times independently. All primers (Table.1) for examining gene expression were purchased from Sangon Biotech. Gene expression was normalized to $\beta$ actin to determine the fold change in gene expression between the test sample and control sample!

\subsection{Statistical analysis}

Data were expressed as mean \pm standard deviation (mean \pm SD). All cell experiments were repeated three times. One-way analysis of variance (ANOVA) and post-hoc Tukey's test were performed to determine differences due to treatment after confirming homoscedasticity and normality for data. Statistically significant differences were recognized at a level of $p<0.05$.

\section{Results}

\subsection{Chemical analysis of TR-PM}

The average concentrations of 16 PAHs were measured and presented in Table 2 . The average concentrations of 16 PAHs varied from $0.42 \pm 0.06$ to $12.56 \pm 3.14 \mathrm{ng} / \mathrm{m}^{3}$, and the sum was $63.98 \mathrm{ng} / \mathrm{m}^{3}$. The top seven categories are shown in Fig. 2, BbF was the highest one which accounted for $19.73 \%$ of the total PAHs. The levels of 4-ring, 5-ring, and 6-ring were $21.22,27.34$, and $6.52 \mathrm{ng} / \mathrm{m}^{3}$, respectively.

As shown in Table 3, the average concentrations of OC and EC in the samples were $13.21 \pm 0.33 \mu \mathrm{g} / \mathrm{m}^{3}$ and $4.28 \pm 0.04 \mu \mathrm{g} / \mathrm{m}^{3}$, respectively. OC was higher than EC, the ratio of OC / EC is $3.09 \pm 0.08$.

\subsection{Inflammatory cell counts in BALF}

To evaluate the effects of TR-PM on lung inflammation induced by OVA, the total number and differential cell counts were determined from the collected BALF (Fig. 3). OVA + TR-PM significantly increased the total cell and macrophage numbers compared with controls, OVA alone, and TR-PM alone groups (A). TRPM resulted in a remarkable elevation of neutrophil numbers compared with controls. OVA + TR-PM significantly increased the number of neutrophils compared with controls, OVA alone, and TR-PM alone groups (B). OVA + TR-PM significantly increased eosinophil numbers compared with controls, OVA alone, and TR-PM alone groups (C). Furthermore, OVA + TR-PM significantly increased lymphocyte numbers compared with controls, OVA alone and TR-PM 2.5 alone groups, but TR-PM alone did not (D). 


\subsection{The contents of IL-4,IL-17A and IL-10 in BALF}

To investigate the effect of the TR-PM on OVA-induced lung inflammation, the protein levels of proinflammatory molecules in BALF were measured. As showed in Fig. 4, treatment with TR-PM accompanied with OVA markedly exacerbated Th-2 cytokines IL-4 over the controls, OVA alone and TRPM alone (A). TR-PM alone significantly increased Th-17 cytokines IL-17A compared with the control groups, TR-PM accompanied with OVA markedly increased IL-17A compared with the controls, OVA alone and TR-PM alone (B). Instillation of OVA + TR-PM significantly decreased the IL-10 compared with controls, OVA alone and TR-PM alone, but not TR-PM alone (C).

\subsection{TR-PM enhanced plasma OVA-specific IgE}

To examine whether the $\mathrm{PM}_{2.5}$ had an adjuvant activity on antigen-specific Ig production in the plasma, OVA-specific IgE in the plasma was measured (Fig. 5). OVA alone induced a significantly more OVAspecific IgE expression compared with the control. Combined treatment with OVA and TR-PM significantly elevated OVA-specific IgE production compared with controls, OVA alone and TR-PM alone.

\subsection{TR-PM induced pathologic changes}

As shown in Fig. 6A, the control mice generally had a normal lung morphology, no visible neutrophils, and few macrophages in peribronchiolar regions or alveolar parenchyma were observed. The lung tissues of the mice in the OVA groups (Fig. 6B), neutrophils influx into the lungs, and peribronchiolar thickening were clearly apparent. In the TR-PM group, large areas of inflammatory cell infiltration were observed around the bronchial walls (Fig. 6C). Furthermore, in the OVA + TR-PM group (Fig. 6D), the structure of lung tissue is disordered, a minimal amount of alveolar cavity collapse or enlargement, thickening of alveolar walls with much inflammatory infiltration around the airway and blood vessels.

\subsection{IL-4,IL-17A and IL-10 mRNA expression}

To assess the inflammatory response in lung tissue, we measured the expression of IL-4,IL-17A, IL-10 mRNA. As shown in Fig. 7, TR-PM alone upregulated IL-4 significantly compared with controls. The combined treatment of OVA and TR-PM significantly increased the expression of IL-4 compared with controls, OVA, and TR-PM alone (A). Significant increases were found in IL-17A expression compared with controls in OVA and TR-PM alone. Combined treatment of OVA and TR-PM significantly increased the expression of IL-17A too, compared with controls, OVA, and TR-PM alone (B). Meanwhile, we found a significant decrease in IL-10 expression compared with controls in OVA alone and TR-PM alone (C).

\section{Discussion}

As a significant environmental risk factor, $\mathrm{PM}_{2.5}$ has been considered a great threat to human health (Zhao et al., 2020). PM $_{2.5}$ can readily trigger asthma, bronchitis and other diseases (Var-doulakis and 
Osborne, 2018; Bouazza et al., 2018). Sources of $\mathrm{PM}_{2.5}$ could be industrial, traffic emissions, bio combustion and raise dust. Among these sources, traffic emissions make an important contribution in cities (Song et al., 2014). Traffic-related air pollution, represented by nitrogen dioxide $\left(\mathrm{NO}_{2}\right)$ and PAHs, has got more attention in developed countries. Numerous epidemiologic studies have reported its association with childhood asthma (Brunekreef and Sunyer, 2003; Gasana et al., 2012; Jerrett et al., 2008). However, there is limited experimental evidence addressing the relationship between TR-PM and the development of asthma. The polycyclic aromatic compounds of $\mathrm{PM}_{2.5}$, the organic constituents with high toxicity, could cause bronchial mucosal injury, alveolar epithelial tissue hyperplasia, and chronic inflammation (He et al., 2017; Yang et al., 2016). Some studies have emphasized the toxicity of PAHs absorbed on $\mathrm{PM}_{2.5}$. Still, most of the exposure analyses were carried out by mixing collected $\mathrm{PM}_{2.5}$ samples, which cannot accurately represent the ambient $\mathrm{PM}_{2.5}$ in a specific region. In this study, we collected $\mathrm{PM}_{2.5}$ from a roadside with a large average daily traffic volume, and we used a mouse model of acute TR-PM and OVA exposure. We showed that TR-PM exposure exacerbated OVA-induced allergic inflammation. This sensitization inflammation involved increased inflammatory cells and proinflammatory cytokines in the BALF, and increased lung injury. Furthermore, the expression of IL-4, IL-17A was increased, while IL-10 was decreased.

Airways are tended to be irritated by inhaling stimulating substances, which may provoke allergic reactions for developing asthma (Wang et al., 2019). A previous study showed that $\mathrm{PM}_{2.5}$ extract exposure disrupted airway epithelial barrier function and increased airway inflammation when challenged with an aerosol allergen (Zhao et al., 2020). The pathological features of asthma include chronic airway inflammation, airway hyperresponsiveness (AHR), and airway remodeling of both large and small conducting airways (Zhao et al., 2020). Airway inflammation is the basic pathological change of allergic asthma, characterized by infiltration and accumulation of inflammatory cells in the airway, including lymphocytes, eosinophils, neutrophils, endothelial cells, and macrophages (Al-Shami et al., 2005; Jember et al., 2001). Inflammatory cell recruitment and pro-inflammatory cytokines release occur when humans and animals are exposed to $\mathrm{PM}_{2.5}$ (Gualtieri et al., 2010). The inflammatory cells infiltration has been found in patients with asthma (Fahya et al., 1995). In this study, our results showed that administration of OVA together with TR-PM significantly increased the lymphocytes, eosinophils, neutrophils, endothelial cells in BALF, indicating that TR-PM exposure could trigger the development of severe allergic airway inflammation in the sensitization process, which was caused by a large number of immune cells entering the alveoli.

Several studies have shown that immune cells and cytokines play an essential role in the pathogenesis of allergic asthma, especially the changes of $C D 4^{+} T$ cell subsets (Th1, Th2, Th17, and regulatory CD $4^{+} T$ cells) and cytokines such as IL-4, IL-5, and IL-17. Excessive release of Th2 cytokines has been proved to play an important role in the development and progression of allergic asthma (Komai et al., 2003; Tang et al., 2021). Some researchers found that $\mathrm{PM}_{2.5}$ could aggravate the imbalance of Th1/Th2 and Th17/Treg pathways through inflammation in airway and lung (Jiang et al., 2014; Dobreva et al., 2015). Increased secretion of the Th2-associated cytokines IL-4, IL-5, and IL-13 were reported in asthma, participating in 
goblet cell metaplasia, airway eosinophilia, and progression of chronic inflammation of the airway and asthma (Chupp et al., 2020; Kudo et al., 2013). IL-4 has been involved in the formation of inflammatory responses in COPD and allergic asthma, its level could partially reflect the severity of airway inflammation (Kaufman et al., 2007). In our study, TR-PM plus OVA increased the level of IL-4, indicating that Th2 cells increased. This is consistent with the viewpoint that Th1/Th2 imbalance is the pathogenesis of allergic asthma, and confirms the dominant position of Th2 cells in the immune response.

Th17 cells are closely related to the attack of some autoimmune diseases and inflammatory reactions. They can induce the aggregation of neutrophils and the secretion of colony-stimulating factors, and promote the formation of granulocytes by secreting inflammatory cytokine IL-17. Previous studies have shown that asthma is related to IL-4 and IL- 5 released by Th2 cells and IL-17A released by Th17 cells unique T cell line (Zhou et al., 2019; Lajoie et al., 2010). IL-17A can induce epithelial cells, vascular endothelial cells, neutrophils, eosinophils to release various pro-inflammatory chemokines, including IL-6, CXCL10, and CXCL8. Consistent with previous reports, our results revealed that TR-PM increased Th2 cytokines IL-4, but TR-PM exposure combined with OVA allergen sensitization further increased the IL-4 level. Similarly, OVA sensitization accompanied by TR-PM exposure significantly increased IL-17A compared with the control, OVA alone and TR-PM exposure alone groups,

IL-10, a potent anti-inflammatory and immunoregulatory cytokine produced by multiple activated immune cells, can exert essential functions to maintain tissue homeostasis during infection and inflammation by eliminating dysfunctional mitochondria and inhibiting apoptosis (Ouyang et al., 2010). Studies have shown that the body can increase the synthesis of pro-inflammatory cytokines when IL-10 decreases, leading to a continuous occurrence of airway inflammation, and finally inducing lung tissue destruction, airway remodeling and airflow restriction. It has been reported that IL-10 attenuated the PM 2.5 -induced neutrophilic granulocyte, lymphocyte, and macrophage infiltration, ameliorated alveolar septal thickening, and decreased the production of inflammatory cytokines (Zhang et al., 2021). We showed that OVA sensitization accompanied by TR-PM 2.5 exposure significantly inhibited IL-10 compared with the control, OVA alone, and TR-PM exposure alone groups. Taken together, TR-PM plus OVA up-regulation of Th2, Th17 cytokines and down-regulation of IL-10. Th1, Th2, and Th17 are involved in the development of asthma, indicating that TR-PM accelerated allergic airway inflammation in the sensitization process and may accelerate the development of asthma.

$\lg \mathrm{E}$ is an antibody produced by the immune system, which causes allergic reactions in the nose, lungs, throat, and skin (Zahedi et al., 2021). The overproduction of IgE generally causes allergy in response to common environmental antigens. Several factors and cytokines regulate IgE synthesis such as IL-4 and IL-10. IL-4 can induce IgE production which plays an important role in asthma and allergic reactions (Van Der Pouw Kraan et al., 1998). It has been reported that urban $\mathrm{PM}_{2.5}$ increases the OVA-specific IgE (He et al., 2016). In the present study, we found that IgE increased significantly in the OVA + TR-PM group compared with OVA exposure alone. We speculated that TR-PM promoted the synthesis of IgE. 
TR-PM exposure combined with OVA sensitization caused lung inflammation in mice, an effect demonstrated by increased inflammatory cell numbers and cytokines in BALF. The results were supplemented by pathological observations. TR-PM exposure combined with OVA-induced severe infiltration of inflammatory cells around trachea and blood vessels compared with TR-PM and OVA alone groups. Eosinophils infiltration in the airways is a key feature of allergic asthma, contributing to asthma pathogenesis, inflammation, AHR and tissue remodeling (Tang et al., 2021).

To further investigate the mechanism underlying the pro-inflammatory effects of TR-PM treatment on OVA-induced lung injury, we investigated the mRNA expression of IL-4, IL-17A, and IL-10. The results showed that TR-PM plus OVA exposure further up-regulated the mRNA expression of IL-4 and IL-17A, but down-regulated the IL-10 mRNA.

\section{Conclusion}

Taken together, we found that TR-PM markedly increased the numbers of neutrophilic granulocyte, lymphocyte, and macrophage as well as levels of IgE in lung tissues. IL-4 and IL-17A levels in BALF were significantly increased, but IL-10 was decreased. TR-PM exposure combined with OVA allergen sensitization exacerbated the inflammatory cells infiltration and pulmonary injury. These findings indicate that TR-PM triggers the development of severe allergic inflammation and lung injury in the sensitization process, and accelerates the development of asthma.

\section{Declarations}

\section{Acknowledgment}

The authors would like to express their gratitude to EditSprings (https://www.editsprings.com/) for the expert linguistic services provided.

\section{Ethics approval and consent to participate}

Current study which involves animal subjects has been reviewed and approved by Shanxi University's Institutional Animal Care and Use Committee (Approved Animal Use Protocol Number: HZ20180503).

\section{Consent for publication}

No applicable

\section{Availability of data and materials}

No applicable

\section{Competing interests}

The authors declare that they have no competing interests. 


\section{Funding}

This work was supported by the National Nature Science Foundation of China (No. 42177215), and the Natural Science Foundation of Shanxi Province (No. 201901D111005).

\section{Authors' contributions}

All authors contributed to the study conception and design. Material preparation, data collection and analysis were performed by Huan Yu, Lifeng Zhang and Zhenyu Dong. The first draft of the manuscript was written by Haiying Wei and all authors commented on previous versions of the manuscript. All authors read and approved the final manuscript.

\section{References}

Abdel-Shafy HI, Mansour MSM (2016) A review on polycyclic aromatic hydrocarbons: source, environmental impact, effect on human health and remediation. Egypt J Pet 25:107-123. https://doi.org/10.1016/j.ejpe.2015.03.011

Al-Shami A, Spolski R, Kelly J, Keane-Myers A, Leonard WJ (2005) A role for TSLP in the development of inflammation in an asthma model. J Exp Med 202(6): 829-39. https://doi.org/10.1084/jem.20050199

An F, Liu J, Lu W, Jareemit D (2021) A review of the traffic-related air pollution around schools in student health and its mitigation. J Transp Health 23:101249.https://doi.org/10.1016/j.jth.2021.101249

Bein KJ, Wexler AS (2015) Compositional variance in extracted particulate matter using different filter extraction techniques. Atmos Environ 107: 24-34. https://doi.org/10.1016/j.atmosenv.2015.02.026

Bouazza N, Foissac F, Urien S, Guedj R, Carbajal R, Treluyer JM, Chappuy H (2018) Fine particulate pollution and asthma exacerbations. Arch Dis Child 103 (9):828-

831. https://dx.doi.org/10.1136/archdischild-2017-312826

Brunekreef B, Sunyer J (2003) Asthma, rhinitis and air pollution: is traffic to blame? Eur Respir J 21: 913915. https://doi.org/10.1183/09031936.03.00014903

Carosino CM, Bein KJ, Plummer LE, Castaneda AR, Zhao Y, Wexler AS, Pinkerton KE (2015) Allergic airway inflammation is differentially exacerbated by daytime and nighttime ultrafine and submicron fine ambient particles:heme oxygenase-1 as an indicator of PM-mediated allergic inflammation. J Toxicol Environ Health A 78: 254-266. https://doi.org/10.1080/15287394.2014.959627

Chow JC, Watson JG, Chen LWA, Chang MCO, Robinson NF, Trimble D, Kohl S (2007) The IMPROVE_A temperature protocol for thermal/optical carbon analysis: maintaining consistency with a long-term database. J Air Waste Manage Assoc 57:1014-1023. https://doi.org/10.3155/1047-3289.57.9.1014 
Chupp GL, Kaur R, Mainardi A (2020) New Therapies for Emerging Endotypes of Asthma. Annu Rev Med 71: 289-302. https://doi.org/10.1146/annurev-med-041818-020630

Dai Q, Bi X, Wu J, Zhang Y, Wang J, Xu H, Yao L, Jiao L, Feng YC (2015) Characterization and source identification of heavy metals in ambient $\mathrm{PM}_{10}$ and $\mathrm{PM}_{2.5}$ in an integrated iron and steel industry zone compared with a background site. Aerosol Air Qual Res 15 (3): 875-887.

https://doi.org/10.4209/aaqr.2014.09.0226

Dobreva ZG, Kostadinova GS, Popov BN, Petkov GS, Stanilova SA (2015) Proinflammatory and antiinflammatory cytokines in adolescents from Southeast Bulgarian cities with different levels of air pollution. Toxicol Ind Health 31 (12): 1210-1217. https://doi.org/10.1177/0748233713491812

Edginton S, Dylan E, O'Sullivan DE, King WD, Lougheed MD (2021) The effect of acute outdoor air pollution on peak expiratory flow in individuals with asthma: A systematic review and meta-analysis. Environ Res 192 :110296. https://doi.org/10.1016/j.envres.2020.110296

Fahya JV, Kimb KW, Liu J, Boushey HA (1995) Prominent neutrophilic inflammation in sputum from subjects with asthma exacerbation. J Allergy Clin Immunol 95:843-852. https://doi.org/10.1016/s00916749(95)70128-1

Gasana J, Dillikar D, Mendy A, Forno E, Vieira ER (2012) Motor vehicle air pollution and asthma in children: a meta-analysis. Environ Res 117: 36-45. https://doi.org/10.1016/j.envres.2012.05.001

Gehring U, Beelen R, Eeftens M, Hoek G, Brunekreef B (2015) Particulate matter composition and respiratory health: the piama birth cohort study. Epidemiology 26 (3): 300-309.

https://doi.org/10.1097/EDE.0000000000000264

Gehring U, Wijga AH, Hoek G, Bellander T, Berdel D, Bruske I, Fuertes E, Gruzieva O, Heinrich J, Hoffmann B, Jongste JC, Klumper C, Koppelman GH, Korek M, Kramer U, Maier D, Melen E, Pershagen G, Brunekreef B (2015) Exposure to air pollution and development of asthma and rhino conjunctivitis throughout childhood and adolescence: a population-based birth cohort study. Lancet Respir Med 3: 933-942. https://doi.org/10.1016/S2213-2600(15)00426-9

Gorai AK, Tchounwou PB, Tuluri F (2016) Association between ambient air pollution and asthma prevalence in different population groups residing in eastern Texas, USA. Int $J$ Environ Res Public Health 13 (4): 378. https://doi.org/10.3390/ijerph13040378

Gualtieri M, Ovrevik J, Holme JA, Perrone MG, Bolzacchini E, Schwarze PE, Camatini M (2010) Differences in cytotoxicity versus pro-inflammatory potency of different PM fractions in human epithelial lung cells. Toxicol In Vitro 24: 29-39. https://doi.org/10.1016/j.tiv.2009.09.013

Guo S, Hu M, Peng J (2020) Remarkable nucleation and growth of ultrafine particles from vehicular exhaust. Proc Natl Acad Sci U.S.A. 117: 3427-3432. https://doi.org/10.1073/pnas.1916366117. 
Gutierrez-Castillo ME, Roubicek DA, Cebrian-Garcia, Vizcaya-Ruiz AD, Sordo-Cedeno M, Ostrosky-Wegman $P(2006)$ Effect of chemical composition on the induction of DNA damage by urban airborne particulate matter. Envion Mol Mutagen 47(3): 199-211. https://doi.org/10.1002/em.20186

He M, Ichinose T, Yoshida S, Ito T, He C, Yoshida Y, Arashidani K, Takano H, Sun G, Shibamoto T (2017) $\mathrm{PM}_{2.5}$-induced lung inflammation in mice: Differences of inflammatory response in macrophages and type II alveolar cells. J Appl Toxicol 37(10): 1203-1218. https://doi.org/10.1002/jat.3482

Jember AGH, Zuberi R, Liu FT, Croft M (2001) Development of allergic inflammation in a murine model of asthma is dependent on the costimulatory receptor OX40. J Exp Med 193: 387-392. https://doi.org/10.1084/jem.193.3.387

Jerrett M, Shankardass K, Berhane K, Gauderman WJ, Kunzli N, Avol W, Gilliland F, Lurmann F, Molitor JN, Molitor JT, Thomas DC, Peters J, Mcconnell R (2008) Traffic-related air pollution and asthma onset in children: a prospective cohort study with individual exposure measurement. Environ Health Perspect 116: 1433-1438. https://doi.org/10.1289/ehp.10968

Jiang L, Diaz PT, Best TM, Stimpfl JN, He F, Zuo L (2014) Molecular characterization of redox mechanisms in allergic asthma. Ann Allergy Asthma Immunol 113 (2): 137-142. https://doi.org/10.1016/j.anai.2014.05.030

Kaufman JD (2007) Air Pollution and Mortality: Are We Closer to Understanding the How? Am J Resp Crit Care 176(4): 325-326. https://doi.org/10.1164/rccm.200705-647ED

Kaur S, Nieuwenhuijsen MJ, Colvile RN (2007) Fine particulate matter and carbon monoxide exposure concentrations in urban street transport microenvironments. Atmos Environ 41: 4781-4810. https://doi.org/10.1016/j.atmosenv.2007.02.002

Kirrane EF, Luben TJ, Benson A, Owens EO, Sacks JD, Dutton SJ, Madden M, Nichols JL (2019) A systematic review of cardiovascular responses associated with ambient black carbon and fine particulate matter. Environ Int 127: 305-316. https://doi.org/10.1016/j.envint.2019.02.027

Komai M, Tanaka H, Masuda T, Nagao K, Ishizaki M, Sawada M, Nagai H (2003) Role of Th2 responses in the development of allergen-induced airway remodelling in a murine model of allergic asthma. $\mathrm{Br} \mathrm{J}$ Pharmacol 138: 912-920. https://doi.org/10.1038/sj.bjp.0705105

Krall JR, Anderson GB, Dominici F, Bell ML, Peng RD (2013) Short-term exposure to particulate matter constituents and mortality in a national study of U.S. Urban communities. Environ Health Perspect 121 (10): 1148-1153. https://doi.org/10.1289/ehp.1206185

Krall JR, Mulholland JA, Russell AG, Balachandran S, Winquist A, Tolbert PE, Waller LA, Sarnat SE (2017) Associations between source-specific fine particulate matter and emergency department visits for 
respiratory disease in four us cities. Environ Health Perspect 125 (1): 97-

103. https://doi.org/10.1289/EHP271

Kudo M, Ishigatsubo Y, Aoki I (2013) Pathology of asthma. Front Microbiol 4: 263. https://doi.org/10.3389/fmicb.2013.00263

Lajoie S, Lewkowich IP, Suzuki Y, Clark JR, Sproles AA, Dienger K, Budelsky AL, Wills-Karp M (2010) Complement-mediated regulation of the interleukin IL-17A axis is a central genetic determinant of the severity of experimental allergic asthma. Nat Immunol 11(10): 928-935. https://doi.org/10.1038/ni.1926

Li R, Kou X, Geng H, Dong C, Cai Z (2014) Pollution characteristics of ambient PM 2.5 -bound PAHs and NPAHs in a typical winter time period in Taiyuan. Chin Chem Lett 25: 663-666.

http://dx.doi.org/10.1016/j.cclet.2014.03.032

Li Y, Zhou J, Rui X, Zhou L, Mo X (2019) $\mathrm{PM}_{2.5}$ exposure exacerbates allergic rhinitis in mice by increasing DNA methylation in the IFN-y gene promoter in CD4+T cells via the ERK-DNMT pathway. Toxicol Lett 301: 98-107. https://doi.org/10.1016/j.toxlet.2018.11.012

Loftus C, Yost M, Sampson P, Arias G, Torres E, Vasquez VBV, Bhatti P, Karr C (2015) Regional PM 2.5 and asthma morbidity in an agricultural community:a panel study. Environ Res 136: 505-512. https://doi.org/10.1016/j.envres.2014.10.030

Mimura T, Ichinose S, Yamagami H, Fujishima H, Kamei Y, Goto M, Takada S, Matsubara M (2014) Airborne particulate matter $\left(\mathrm{PM}_{2.5}\right)$ and the prevalence of allergic conjunctivitis in Japan. Sci Total Environ 4874: 93-499. https://doi.org/10.1016/j.scitotenv.2014.04.057

Ouyang W, Rutz S, Crellin NK, Valdez PA, Hymowitz SG (2011) Regulation and functions of the IL-10 family of cytokines in inflammation and disease. Annu Rev Immunol 29: 71-109.

https://doi.org/10.1146/annurev-immunol-031210-101312

Peng RD, Bell ML, Geyh AS, Dermott A, Zeger SL, Samet JM, Dominici F (2009) Emergency admissions for cardiovascular and respiratory diseases and the chemical composition of fine particle air pollution. Environ Health Perspect 117 (6): 957-963. https://doi.org/10.1289/ehp.0800185

Pinkerton KE, Chen CY, Mack SM, Upadhyay P, Wu CW, Yuan W (2019) Cardiopulmonary health effects of airborne particulate matter: correlating animal toxicology to human epidemiology. Toxicol Pathol 47, 954961.https://doi.org/10.1177/0192623319879091

Rönkkö T, Kuuluvainen H, Karjalainen P (2017) Traffic is a major source of atmospheric nanocluster aerosol. P Natl Acad Sci USA 114: 7549-7554. https:// doi.org/10.1073/pnas.1700830114

Song S, Wu Y, Zheng X, Wang Z, Yang L, Li J, Hao J (2014) Chemical characterization of roadside PM 2.5 and black carbon in Macao during a summer campaign. Atmos Pollut Res 5: 381-387. 
Sun X, Wei H, Young D, Bein KJ, Smiley-Jewell SM, Zhang Q, Fulgar CCB, Castaneda AR, Pham AK, Li W, Pinkerton KE (2017) Differential pulmonary effects of wintertime California and China particulate matter in healthy young mice. Toxicol Lett 278: 1-8. https://doi.org/10.1016/j.toxlet.2017.07.853

Tang W, Dong M, Teng F, Cui J, Zhu X, Wang W, Wuniqiemu T, Qin J, Yi L, Wang S, Dong J, Wei Y (2021) TMT-based quantitative proteomics reveals suppression of SLC3A2 and ATP1A3 expression contributes to the inhibitory role of acupuncture on airway inflammation in an OVA-induced mouse asthma model. Biomed Pharmacother 134: 111001. https://doi.org/10.1016/j.biopha.2020.111001

Van Der Pouw Kraan TCTM, Van Der Zee JS, Boeije LCM, De Groot ER, Stapel SO, Aarden LA, Der Zee V, Groot DE (1998) The role of IL-13 in IgE synthesis by allergic asthma patients. Clin Exp Immunol 111: 129-135. https://doi.org/10.1046/j.1365-2249.1998.00471.x

Var-doulakis S, Osborne N (2018) Air pollution and asthma. Arch Dis Child 103 (9): 813. https://doi.org/10.1136/archdischild-2017-314543

Wang P, Liu H, Fan X, Zhu Z, Zhu Y (2019) Effect of San'ao decoction on aggravated asthma mice model induced by $\mathrm{PM}_{2.5}$ and TRPA1/TRPV1 expressions. J Ethnopharmacol 236: 82-90.

https://doi.org/10.1016/j.jep.2019.02.043

Wei H, Zhang Y, Song S, Pinkerton KE, Geng H, Ro CU (2019) Alveolar macrophage reaction to PM2.5 of hazy day in vitro: evaluation methods and mitochondrial screening to determine mechanisms of biological effect. Ecotox Environ Safe 174: 566-573. https://doi.org/10.1016/j.ecoenv.2019.02.093

Wu H, Li Z, Jiang M, Liang C, Zhang D, Wu T, Wang Y, Cribb M (2021) Contributions of traffic emissions and new particle formation to the ultrafine particle size distribution in the megacity of Beijing. Atmosph Environ 262: 118652.https://doi.org/10.1016/j.atmosenv.2021.118652

Yang L, Liu G, Lin Z, Wang Y, He H, Liu T, Kamp DW (2016) Pro-inflammatory response and oxidative stress induced by specific components in ambient particulate matter in human bronchial epithelial cells. Environ Toxicol 31 (8): 923-936. https://doi.org/10.1002/tox.22102

Yuan W, Fulgar CC, Sun X, Vogel CFA, Wu CW, Zhang Q, Bein KJ, Young DE, Li W, Wei H, Pinkerton KE (2020) In vivo and in vitro inflammatory responses to fine particulate matter (PM2.5) from China and California. Toxicol Lett 8 (328): 52-60.

https://doi.org/10.1016/j.toxlet.2020.04.010

Zahedi A, Hassanvand MS, Jaafarzadeh N, Ghadiri A, Shamsipour M, Dehcheshmeh MG (2021) Effect of anbient air $\mathrm{PM}_{2.5}$-bound heavy metals on blood metal (loid)s and children's asthma and allergy proinflammatory (IgE, IL-4 and IL-13) biomarkers. J Trace Elem Med Bio 68: 126826. https://doi.org/ 10.1016/j.jtemb.2021.126826 
Zhang N, Li P, Lin H, Shuo T, Ping F, Su L, Chen G (2021) IL-10 ameliorates $\mathrm{PM}_{2.5}$-induced lung injury by activating the AMPK/SIRT1/PGC-1 a pathway. Envion Toxicol Pharmacol 8:103659.

https://doi.org/10.1016/j.etap.2021.103659

Zhang Y, Li B, Huang C, Yang X, Qian H, Deng Q, Zhao Z, Li A, Zhao J, Zhang X, Qu F, Hu Y, Yang Q, Wang J, Zhang M, Wang F, Zheng X, Lu C, Liu Z, Sun Y, Mo J, Zhao Y, Liu W, Wang T, Carl-Gustaf B, Jan S (2013) Ten cities cross-sectional questionnaire survey of children asthma and other allergies in China. Chin Sci Bull 58: 4182-4189. https://doi.org/10.1007/s11434-013-5914-z

Zhao C, Wang Y, Su Z, Pu W, Niu M, Song S, Wei L, Ding Y, Xu L, Tian M, Wang H (2020) Respiratory exposure to $\mathrm{PM}_{2.5}$ soluble extract disrupts mucosal barrier function and promotes the development of experimental asthma. Sci Total Environ 730: 139145. https://doi.org/10.1016/j.scitotenv.2020.139145

Zhou J, Geng F, Xu J, Peng L, Ye X, Yang D, Zhao J, Sun Q (2019) $\mathrm{PM}_{2.5}$ exposure and cold stress exacerbates asthma in mice by increasing histone acetylation in IL-4 gene promoter in CD4 ${ }^{+} \mathrm{T}$ cells. Toxicol Lett 316: 147-153. https://doi.org/10.1016/j.toxlet.2019.09.011

\section{Tables}

Due to technical limitations, table 1, 2, 3 is only available as a download in the Supplemental Files section.

\section{Figures}




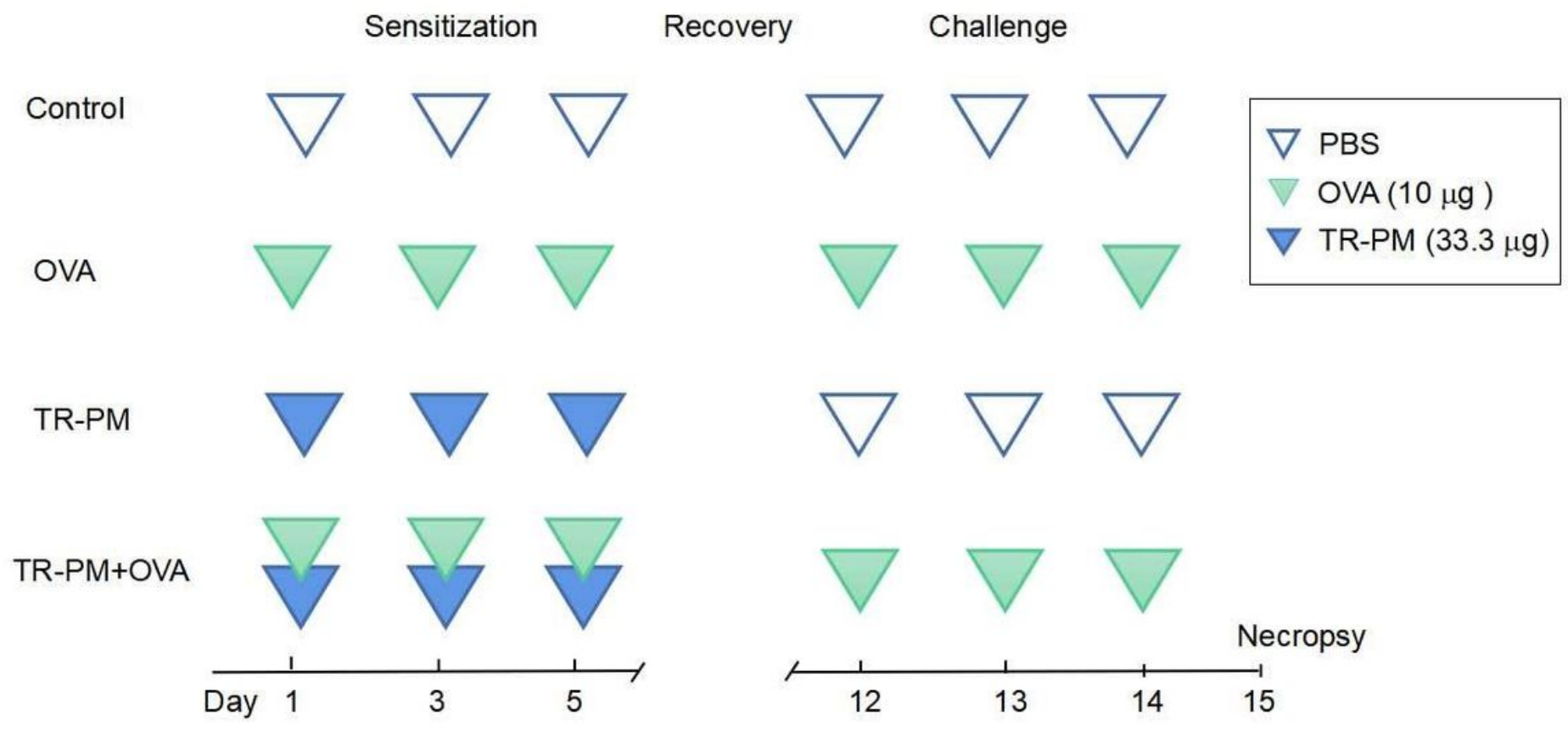

Figure 1

Exposure protocol 


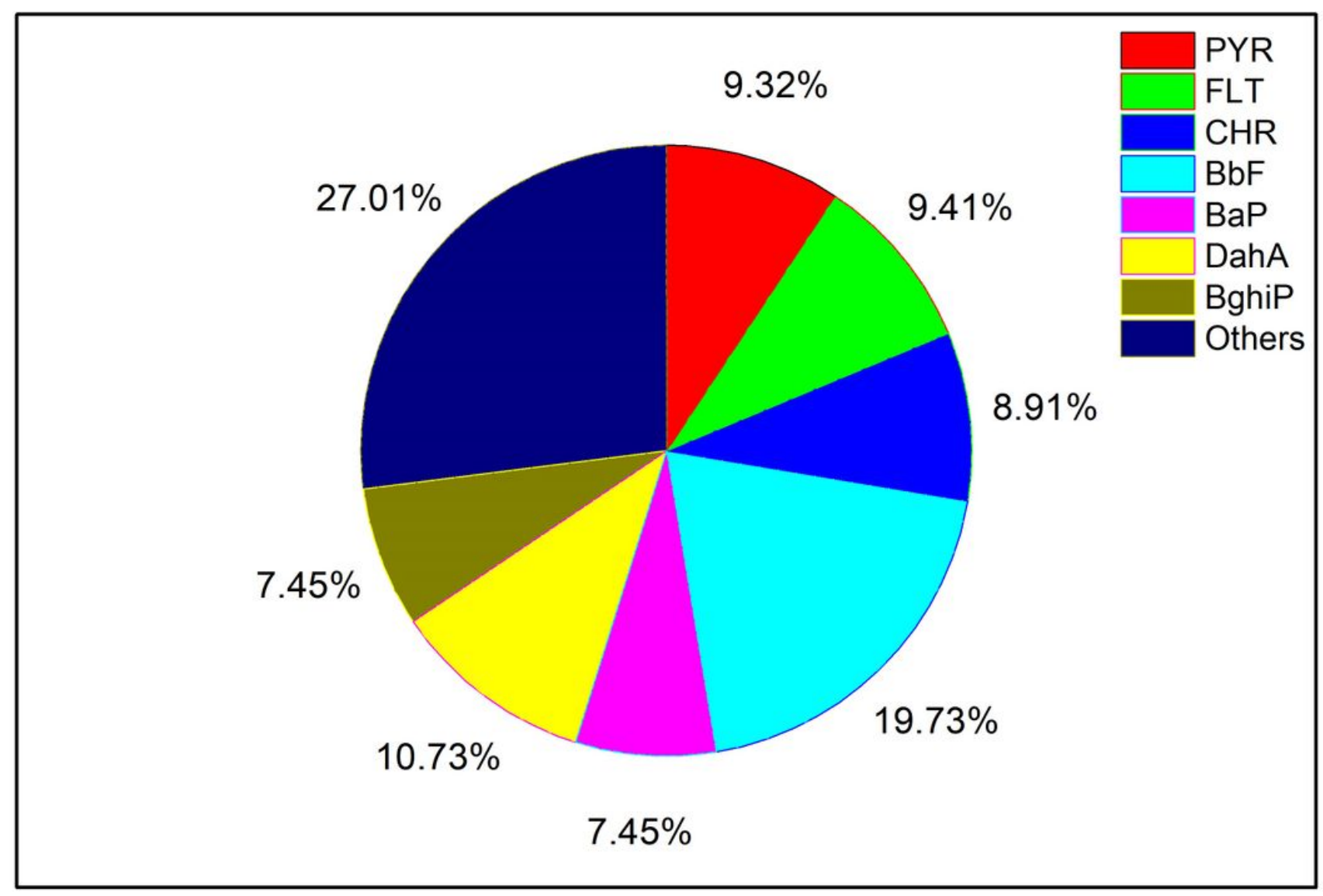

Figure 2

Average concentration of top seven PAHs in TR-PM 


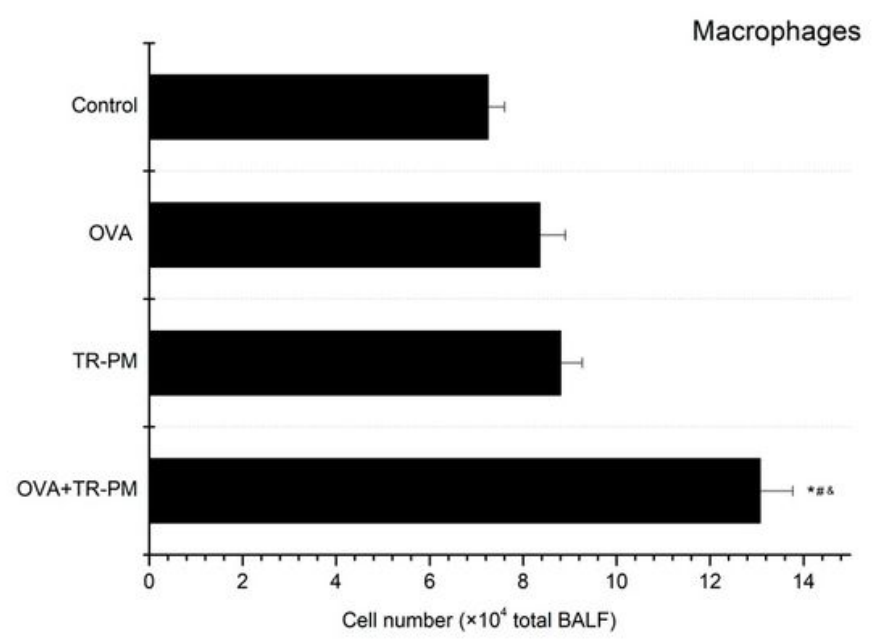

a

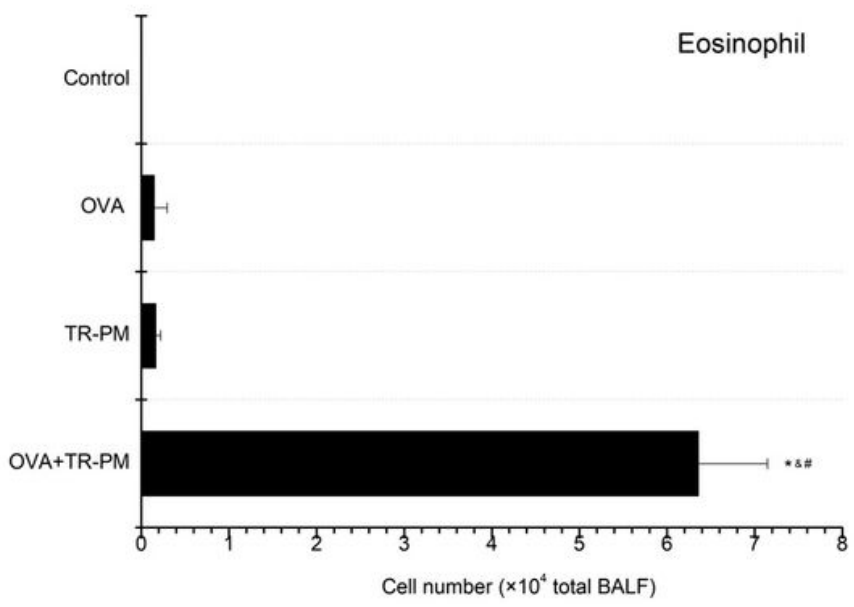

c

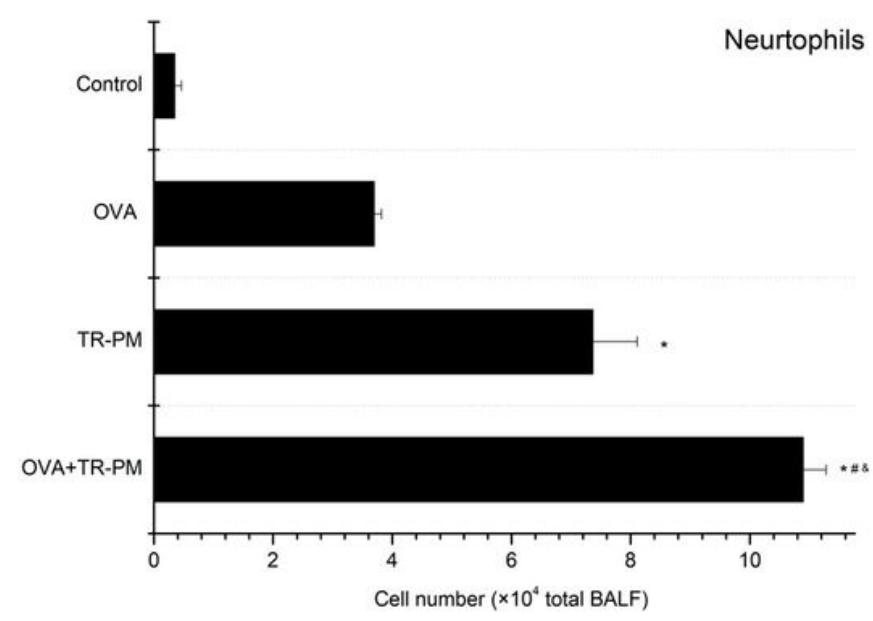

b

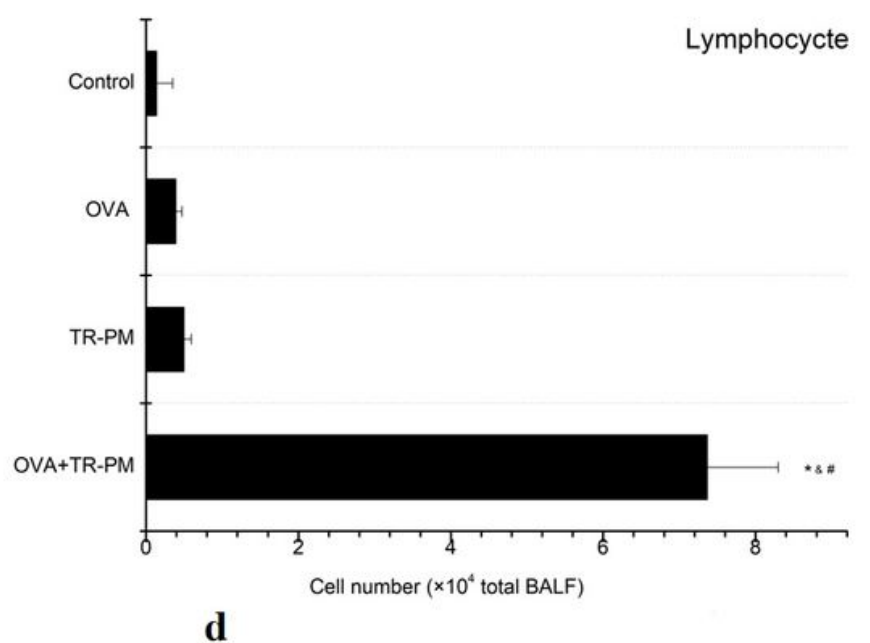

\section{Figure 3}

Differential cell count of BAL fluid. (A)Macrophage numbers; (B) Neutrophil numbers; (C) Eosinophils numbers; (D) Lymphocyte numbers. Data are presented as mean (SEM) from 6 animals. * indicates a significant difference to control. \# indicates a significant difference to OVA alone. 『indicates a significant difference to TR-PM alone ( $p<0.05$ by one-way ANOVA).
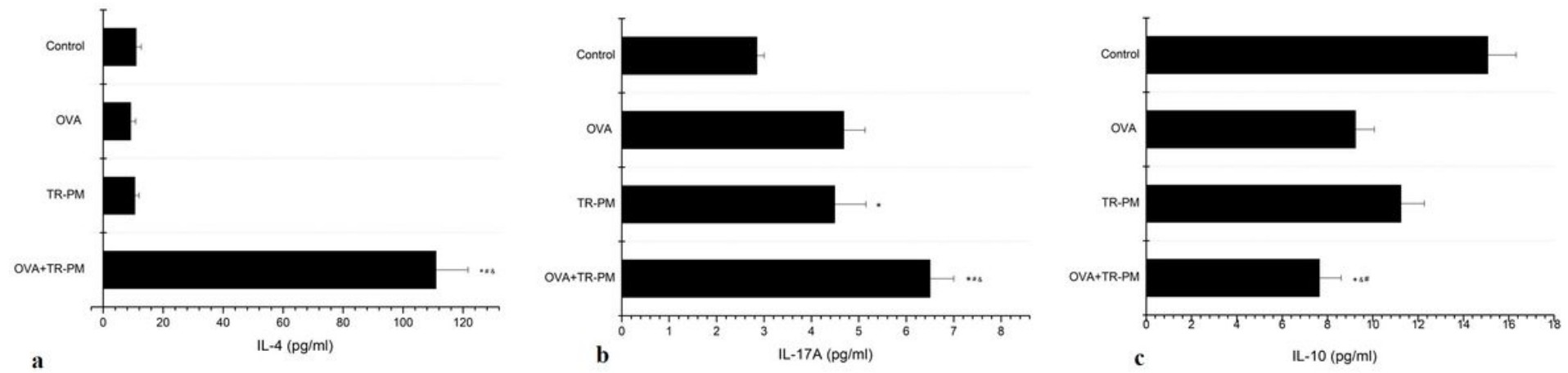


\section{Figure 4}

The protein levels of inflammatory cytokines in BALF. (A) IL-4; (B) IL-17A; (C) IL-10; Data is presented as mean (SEM) from 6 animals. *indicates a significant difference to control. \#indicates a significant difference to OVA alone. 囚indicates a significant difference to TR-PM alone ( $p<0.05$ by one-way ANOVA).

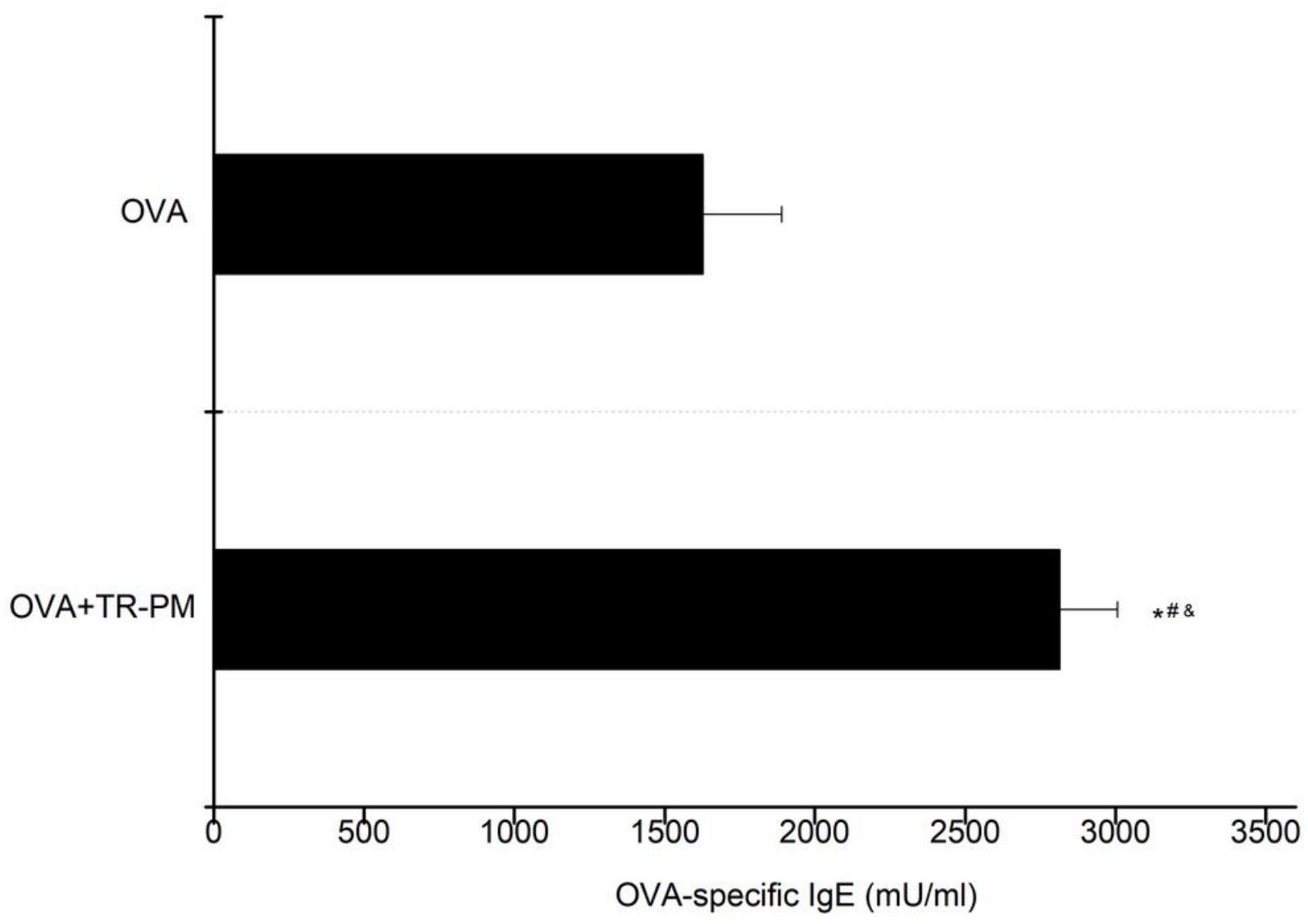

Figure 5

The content of OVA-specific IgE. Data are presented as mean (SEM) from 6 animals. *indicates significant difference to control. Data are presented as mean (SEM) from 6 animals. \# indicates a significant difference to OVA alone. \indicates a significant difference to TR-PM alone $(p<0.05$ by oneway ANOVA). 

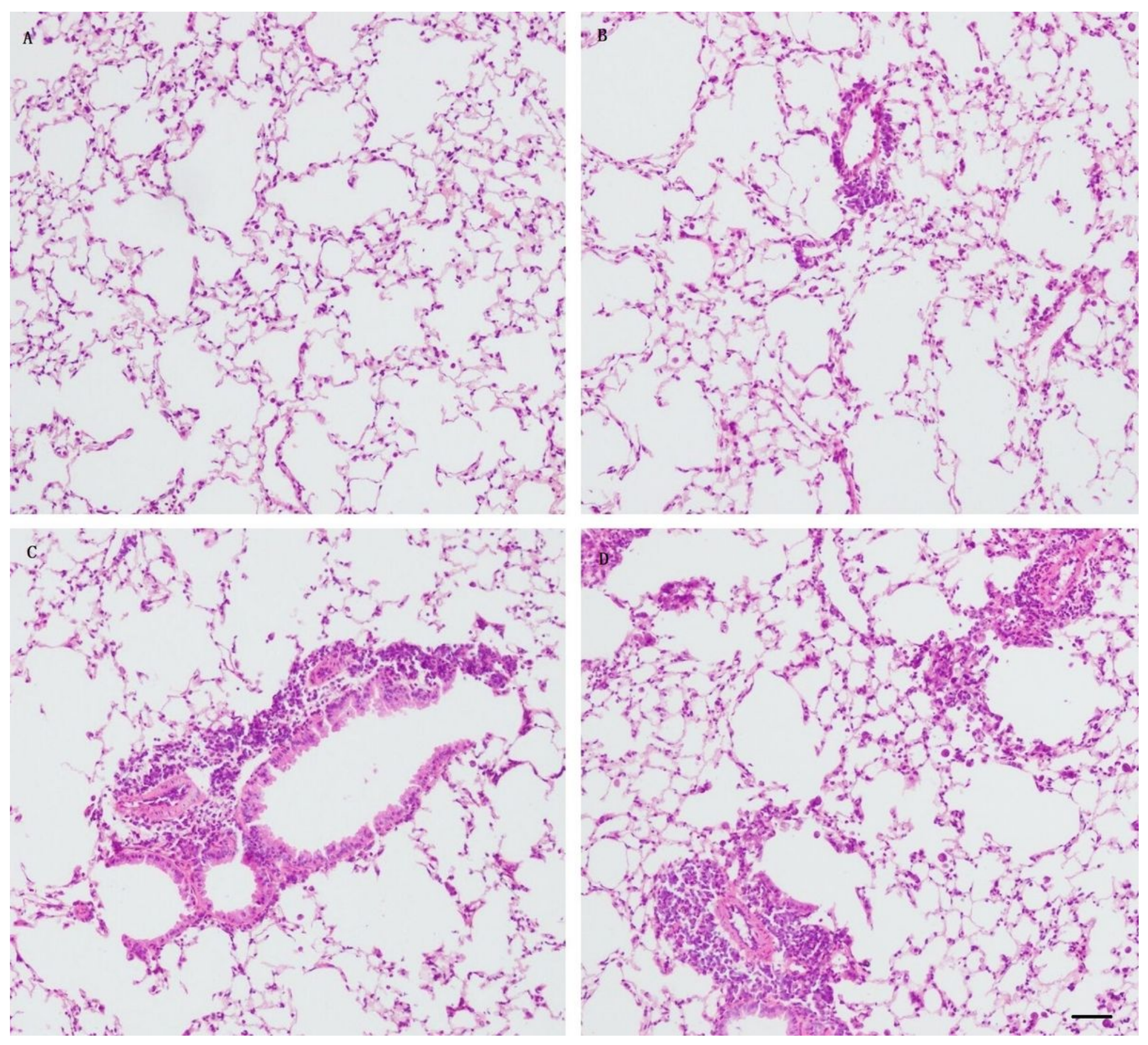

Figure 6

The histopathological slices of lung tissues from the mice exposed to OVA, TR-PM, OVA+TR-PM, and the control. The lung morphological examinations were performed with H\&E staining at a magnification of $100 \mathrm{X}$. A: The control tissue; $\mathrm{B} \bigotimes$ The lung tissue exposed to OVA alone; $\mathrm{C}$ : The lung tissue exposed to TRPM alone; D: The lung tissue exposed to OVA+TR-PM. 

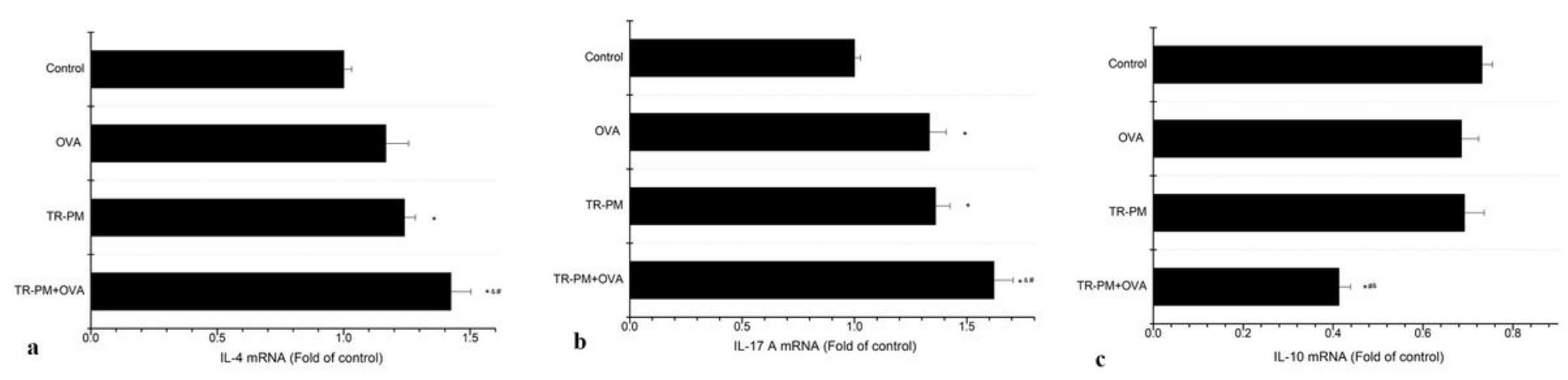

Figure 7

Expression of IL-4 (A), IL-17A (B), IL-10 (C) mRNA in lung tissues measured by RT-PCR. Data are presented as mean (SEM) from 6 animals. * indicates a significant difference to control. \# indicates a significant difference to OVA alone. 囚indicates a significant difference to TR-PM alone ( $p<0.05$ by one-way ANOVA).

\section{Supplementary Files}

This is a list of supplementary files associated with this preprint. Click to download.

- Table1.jpg

- Table2.jpg

- Table3.jpg 